\title{
Yersinia nurmii sp. nov.
}

Correspondence
Johanna Björkroth
johanna.bjorkroth@helsinki.fi

The genus Yersinia belongs to the family Enterobacteriaceae and, at the time of writing, includes the species Y. pestis, $Y$. pseudotuberculosis, Y. enterocolitica, Y. frederiksenii, $Y$. intermedia, Y. kristensenii, Y. bercovieri, Y. mollaretii, $Y$. rohdei, Y. ruckeri, Y. aldovae, Y. aleksiciae, Y. massiliensis and Y. similis. Members of the genus Yersinia are Gram-negative, catalase-positive and oxidase-negative, facultatively anaerobic rods (Bottone et al., 2005).

Strains APN5b-c, ABF6a-c and APN3a-c ${ }^{T}$ were isolated from three packages of broiler meat cuts, packaged under a modified atmosphere. The strains were recovered from VRBG (violet red bile agar with glucose) medium used for the enumeration of enterobacteria in the products. An attempt was made to identify these strains using a $16 \mathrm{~S}$ and $23 S$ rRNA gene HindIII and EcoRI RFLP (ribotype) library for members of the family Enterobacteriaceae, but the patterns did not cluster together with those of any known species.

To study the taxonomic position of these strains, the $16 \mathrm{~S}$ rRNA gene and four housekeeping genes were sequenced and analysed. The partial housekeeping genes $g \ln A$, gyrB, recA and HSP6O - which have been used previously in a multilocus sequence analysis (MLSA) study of Yersinia and

Abbreviation: MLSA, multilocus sequence analysis.

The GenBank/EMBL/DDBJ accession numbers for the 16S rRNA, glnA, gyrB, HSP6O and recA gene sequences determined in this study are FJ717338-FJ717391.

Five supplementary figures and a supplementary table are available with the online version of this paper. have sequence data available for many type strains of Yersinia species - were selected.

In this study, the 16S rRNA gene and housekeeping genes of strains APN5b-c, ABF6a-c and APN3a-c $c^{\mathrm{T}}$ were sequenced in addition to those genes of strains $Y$. aldovae CIP $103162^{\mathrm{T}}, Y$. aleksiciae DSM $14987^{\mathrm{T}}$, Y. enterocolitica subsp. palearctica DSM $13030^{\mathrm{T}}, Y$. enterocolitica subsp. enterocolitica ATCC $9610^{\mathrm{T}}, Y$. intermedia DSM $18517^{\mathrm{T}}, Y$. massiliensis CCUG $53443^{\mathrm{T}}, Y$. pseudotuberculosis CCUG $5855^{\mathrm{T}}$, Y. rohdei DSM $18270^{\mathrm{T}}$, Y. ruckeri ATCC $29473^{\mathrm{T}}$ and Y. similis DSM $18211^{\mathrm{T}}$, which did not have public sequence data available (GenBank accession numbers FJ717338FJ717391).

All strains used in this study were cultured aerobically for $24 \mathrm{~h}$ on blood agar at $30{ }^{\circ} \mathrm{C}$. DNA from the strains was extracted by the guanidium thiocyanate method described by Pitcher et al. (1989) with the addition of $0.6 \mathrm{mg}$ proteinase $\mathrm{K} \mathrm{ml}^{-1}$ to the cell suspension buffer. The $16 \mathrm{~S}$ and $23 \mathrm{~S}$ gene RFLP (ribotyping) procedures were done according to Niskanen et al. (2009). Ribopatterns were scanned and analysed by using the BioNumerics 5.10 software (Applied Maths). Dendrograms were constructed by using UPGMA and the Dice coefficient correlation. Yersinia strains used for ribotyping are presented in Supplementary Fig. S1 (available in IJSEM Online).

The $g \ln A, \operatorname{gyr} B, \operatorname{rec} A$ and $H S P 60$ genes were amplified using primers described by Kotetishvili et al. (2005). The 16S rRNA gene was amplified with primers F19-38 (5'-CTGGCTCAGGAYGAACGCTG-3') and R1541-1522 (5'-AAGG- 
AGGTGATCCAGCCGCA-3'). The PCR cycle for amplification of the HSP60, $g \ln A$ and $r e c A$ genes were described by Kotetishvili et al. (2005). For gyrB, the annealing temperature was increased to $62{ }^{\circ} \mathrm{C}$. The PCR cycles for the $16 \mathrm{~S}$ rRNA gene comprised denaturation at $98{ }^{\circ} \mathrm{C}$ for $2 \mathrm{~min}$, followed by 30 amplification cycles $\left(93{ }^{\circ} \mathrm{C}\right.$ for $1 \mathrm{~min}, 54{ }^{\circ} \mathrm{C}$ for $2 \mathrm{~min}$ and $72{ }^{\circ} \mathrm{C}$ for $2.5 \mathrm{~min}$ ) and final elongation at $72{ }^{\circ} \mathrm{C}$ for $8 \mathrm{~min}$. Each $50 \mu \mathrm{l}$ PCR mixture consisted of $200 \mathrm{mM}$ each dNTP, 1 IU DyNAZyme II DNA polymerase (Thermo Fisher Scientific Inc.) and $0.5 \mu \mathrm{M}$ each primer. PCR products were purified by using the MultiScreen PCR 96 system (Millipore). Bidirectional sequencing of the PCR products was done using an Applied Biosystems BigDye Terminator v3.1 Cycle Sequencing kit and an ABI 3130XL Genetic Analyzer. The consensus sequences of strains APN5b-c, ABF6a-c and APN3a-c $c^{\mathrm{T}}$ were aligned with $16 \mathrm{~S}$ rRNA and housekeeping gene sequences of type and reference strains of other Yersinia species retrieved from GenBank by using BioNumerics 5.10 software (Applied Maths). Only those Yersinia strains that had complete sequence data available for all five genes were used in the comparisons. Maximum-parsimony and neighbourjoining trees with the Jukes-Cantor correction and bootstrap analysis (1000 replicates) were constructed using BioNumerics 5.10 software (Applied Maths). Serratia proteamaculans was used as outgroup in the trees. The phylogenetic trees were constructed using the 16S rRNA gene (1425 bp) and housekeeping genes $\operatorname{gln} A$ (494 bp), gyrB (471 bp), recA (483 bp) and HSP60 (486 bp). Concatenated trees were constructed by combining $g \ln A, \operatorname{gyr} B, \operatorname{rec} A$ and HSP60 gene sequences. The GenBank accession numbers of the $\operatorname{gln} A, \operatorname{grB}, H S P 60$ and $r e c A$ sequences used are presented in Supplementary Table S1 (available in IJSEM Online). The $16 \mathrm{~S}$ rRNA gene sequences of strains APN5b-c, ABF6a-c and APN3a-c ${ }^{T}$ were also compared with those of type species of genera of the family Enterobacteriaceae.

DNA-DNA reassociation was performed at the DSMZ, Braunschweig, Germany. Briefly, DNA was isolated by using a French pressure cell (Thermo Scientific) and purified by chromatography on hydroxyapatite as described by Cashion et al. (1977). DNA-DNA hybridization was carried out as described by De Ley et al. (1970) under consideration of the modifications described by Huß et al. (1983) using a model Cary 100 Bio UV/VIS-spectrophotometer equipped with a Peltier-thermostatted $6 \times 6$ multicell changer and a temperature controller with in situ temperature probe (Varian). The DNA G $+\mathrm{C}$ content of strains APN5b-c, ABF6a-c and APN3a-c ${ }^{T}$ was determined as described by $\mathrm{Xu}$ et al. (2000). The melting-point curves were determined with a LightCycler (Roche Diagnostics) instrument using SYBR Green I dye (Roche Diagnostics). $1 \times$ SSC was used to obtain sharp melting curves. Y. aldovae CIP $103162^{\mathrm{T}}$ was used as the reference organism and $Y$. mollaretii DSM $18520^{\mathrm{T}}$ was used as the control.

The possible pathogenicity of strains APN5b-c, ABF6a-c and APN3a- ${ }^{T}$ was studied by determining the presence of virulence genes virF, inv, ail and yadA (FredrikssonAhomaa et al., 1999), which are used for the identification of pathogenic Y. enterocolitica and Y. pseudotuberculosis. This was of interest because the strains were isolated from food. The virF, inv and ail genes were detected by PCR as described by Niskanen et al. (2009). Each primer for virF, inv or ail was used in a separate PCR. The yadA gene was detected by PCR as described previously (FredrikssonAhomaa et al., 1999). yadA-, inv- and virF-positive $Y$. pseudotuberculosis and yadA-, ail- and virF-positive $Y$. enterocolitica were used as positive controls. Also, virulence-associated pyrazinamidase activity was tested according to Kandolo \& Wauters (1985) at $28{ }^{\circ} \mathrm{C}$ for $48 \mathrm{~h}$, and Congo red dye uptake and calcium-dependent growth at $37{ }^{\circ} \mathrm{C}$ were tested according to Riley \& Toma (1989).

Morphological properties were determined by Gram staining and transmission electron microscopy. Oxidase activity was tested with oxidase strips and catalase activity with $3 \%$ hydrogen peroxide. Biochemical characterization of strains APN5b-c, ABF6a-c, APN3a-c ${ }^{\mathrm{T}}$, Y. similis DSM $18211^{\mathrm{T}}$, Y. mollaretii DSM $18520^{\mathrm{T}}$, Y. bercovieri DSM $18528^{\mathrm{T}}$, Y. kristensenii CIP $80.30^{\mathrm{T}}$, Y. rohdei DSM $18270^{\mathrm{T}}$, Y. ruckeri ATCC $29473^{\mathrm{T}}$, Y. aleksiciae DSM $14987^{\mathrm{T}}$, Y. intermedia DSM $18517^{\mathrm{T}}, Y$. aldovae CIP $103162^{\mathrm{T}}, Y$. enterocolitica subsp. palearctica DSM $13030^{\mathrm{T}}$, Y. frederiksenii DSM $18490^{\mathrm{T}}$, Y. enterocolitica subsp. enterocolitica DSM $4780^{\mathrm{T}}$, Y. massiliensis CCUG $53443^{\mathrm{T}}$ and Y. pseudotuberculosis DSM $8992^{\mathrm{T}}$ was done using the API $20 \mathrm{E}$ and API 50 $\mathrm{CH}$ strips according to instructions of the manufacturer (bioMérieux). The incubation temperature used was $28{ }^{\circ} \mathrm{C}$ and results were read after 24, 48 and $72 \mathrm{~h}$. Each biochemical test was done at least twice. Motility testing was performed at 28 and $37{ }^{\circ} \mathrm{C}$ with Motility Test and Maintenance and Motility Test media (Atlas \& Snyder, 2006).

Strains APN5b-c, ABF6a-c and APN3a-c ${ }^{T}$ had identical glnA (492 bp), gyrB (483 bp), recA (499 bp), HSP60 (510 bp) and 16S rRNA (1452 bp) sequences. Strains shared 97.8-98.7\% 16 rRNA gene sequence similarity with other Yersinia species (Table 1). It has been stated that, within the genus Yersinia, the 16S rRNA gene sequence similarity of the type strains should be $>97.4 \%$. Neighbour-joining trees of members of the genus Yersinia, based on the 16S rRNA and concatenated $g \ln A$, gyrB, recA and HSP60 gene sequences, are presented in Figs 1 and 2, respectively. Trees constructed by the maximumparsimony method are shown in Supplementary Figs S2 and S3 (available in IJSEM Online). Strains APN5b-c, ABF6a-c and APN3a-c ${ }^{T}$ formed a monophyletic group in all phylogenetic trees constructed. The group was separate from other Yersinia species in all individual housekeeping gene trees; in the tree derived from the concatenated $g y r B$, recA and HSP6O gene sequences, Y. ruckeri is the closest phylogenetic neighbour of $Y$. nurmii, with a $100 \%$ bootstrap value. In the trees formed individually from $g \ln A$, recA and HSP60 gene sequences, Y. ruckeri is positioned as the closest phylogenetic neighbour, whereas 
Table 1. 16S rRNA gene sequence similarities of strain APN3a-c ${ }^{\top}$ with representatives of the genus Yersinia

$16 \mathrm{~S}$ rRNA gene sequence similarity was measured over $1432 \mathrm{bp}$.

\begin{tabular}{|c|c|}
\hline Species & $\begin{array}{c}\text { Similarity } \\
(\%)\end{array}$ \\
\hline Y. frederiksenii CCUG $11293^{\mathrm{T}}$ & 98.6 \\
\hline Y. massiliensis CCUG $53443^{\mathrm{T}}$ & 98.3 \\
\hline Y. aleksiciae DSM $14987^{\mathrm{T}}$ & 97.8 \\
\hline Y. bercovieri ATCC $43970^{\mathrm{T}}$ & 98.1 \\
\hline Y. mollaretii ATCC $43969^{\mathrm{T}}$ & 98.7 \\
\hline Y. enterocolitica subsp. palearctica DSM $13030^{\mathrm{T}}$ & 98.0 \\
\hline Y. enterocolitica subsp. enterocolitica ATCC $9610^{\mathrm{T}}$ & 98.1 \\
\hline Y. kristensenii CCUG $33638^{\mathrm{T}}$ & 98.3 \\
\hline Y. rohdei ATCC $43380^{\mathrm{T}}$ & 98.5 \\
\hline Y. intermedia DSM $18517^{\mathrm{T}}$ & 98.3 \\
\hline Y. aldovae CCUG $18770^{\mathrm{T}}$ & 98.4 \\
\hline Y. pseudotuberculosis CCUG $5855^{\mathrm{T}}$ & 97.8 \\
\hline Y. similis $\mathrm{Y} 228^{\mathrm{T}}$ & 97.9 \\
\hline Y. ruckeri ATCC $29473^{\mathrm{T}}$ & 98.0 \\
\hline Y. pestis KIM & 97.9 \\
\hline
\end{tabular}

in the gyrB-derived tree, Y. nurmii was fully separated from the other Yersinia species with a bootstrap value of $100 \%$ (not shown). In the numerical analysis of both HindIII and EcoRI ribopatterns, strains APN5b-c, ABF6a-c and APN3a$\mathrm{c}^{\mathrm{T}}$ clustered together, differing from ribopatterns of type strains of recognized Yersinia species (Supplementary Fig. S1). In phylogenetic analysis of $16 \mathrm{~S}$ rRNA gene sequences of type species of genera of the family Enterobacteriaceae, strains APN5b-c, ABF6a-c and APN3a-c ${ }^{T}$ grouped with Yersinia species (Supplementary Fig. S4, available in IJSEM Online).

DNA-DNA reassociation was carried out, pairing the closest phylogenetic neighbour (according to $H s p 60, g \ln A$ and recA gene analysis) Y. ruckeri ATCC $29473^{\mathrm{T}}$ and two phylogenetically distant species, Y. rohdei DSM $18270^{\mathrm{T}}$ and Y. frederiksenii DSM $18490^{\mathrm{T}}$, with strains APN3a-c $\mathrm{c}^{\mathrm{T}}$ and ABF6a-c, which were chosen to represent the novel species. The values varied from 17.5 to $33.4 \%$, indicating that strains APN3a-c ${ }^{\mathrm{T}}$ and ABF6a-c do not belong to the any of the species studied, including the closest phylogenetic neighbour, Y. ruckeri. The DNA-DNA similarity level between strains APN3a-c ${ }^{T}$ and ABF6a-c was $81.7 \%$. This shows clearly that these strains represent the same species. The DNA G + C content of strains APN5b-c, ABF6a-c and $\mathrm{APN} 3 \mathrm{a}-\mathrm{c}^{\mathrm{T}}$ was $48.7 \pm 0.2 \mathrm{~mol} \%$.

Strains APN5b-c, ABF6a-c and APN3a-c ${ }^{T}$ were negative for virulence marker-encoding genes virF, inv, ail and yadA, did not have Congo red dye uptake or calcium-dependent growth, and were pyrazinamidase-positive.

Strains APN5b-c, ABF6a-c and APN3a-c ${ }^{T}$ were Gramnegative rods. The length of the cells varied between 0.8 and $1.9 \mu \mathrm{m}$ after growth on blood agar for $24 \mathrm{~h}$ at $30{ }^{\circ} \mathrm{C}$ (Supplementary Fig. S5, available in IJSEM Online). The cells had multiple flagella. Colonies were convex and circular and the diameter of the colonies on blood agar after $24 \mathrm{~h}$ at $28{ }^{\circ} \mathrm{C}$ was $1.0-1.5 \mathrm{~mm}$. The strains grew on blood, tryptic soy, MacConkey and nutrient agar at 25$37{ }^{\circ} \mathrm{C}$. Cells were motile at $28{ }^{\circ} \mathrm{C}$ and under microscopic

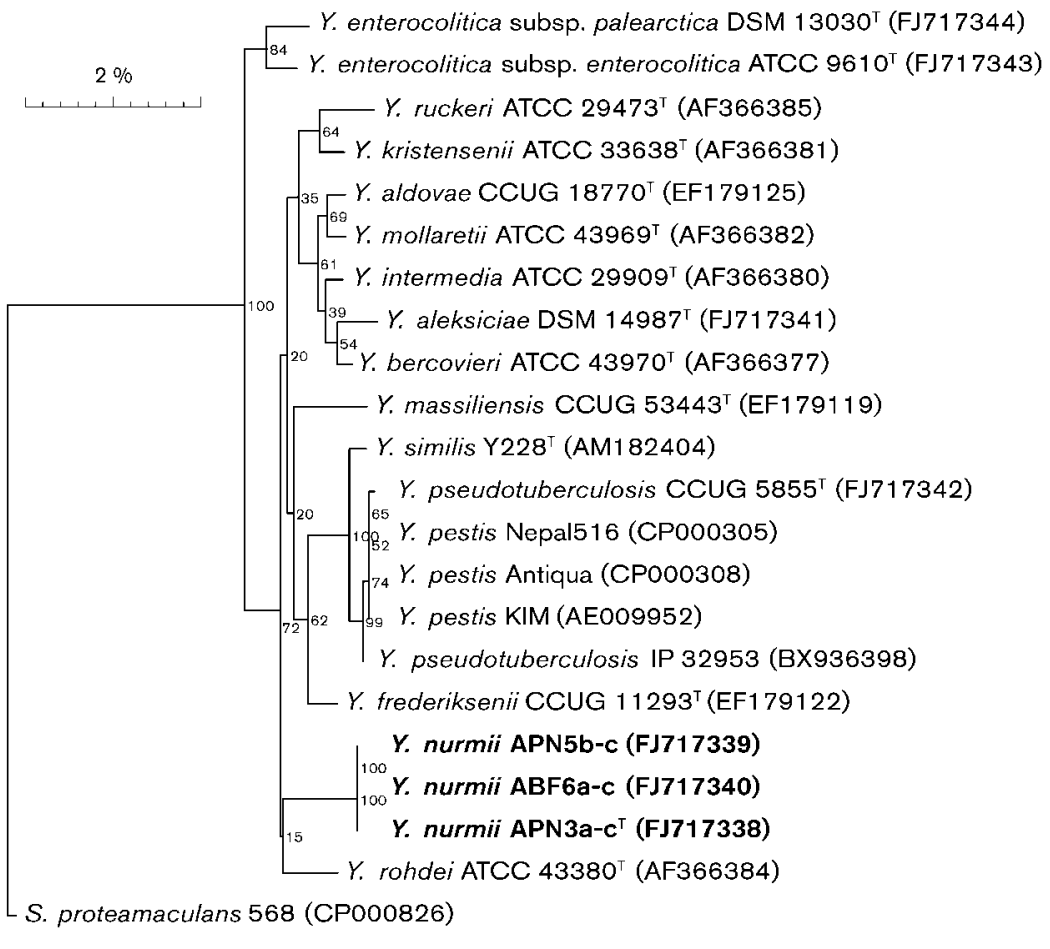

Fig. 1. Neighbour-joining tree based on $16 \mathrm{~S}$ rRNA gene sequences of Yersinia nurmii sp. nov. and type and reference strains of the genus Yersinia. Bootstrap values (\%) for 1000 replicates are given at branch points. $S$. proteamaculans was used as outgroup. GenBank accession numbers are shown in parentheses. Bar, $2 \%$ difference in nucleotide sequence. 


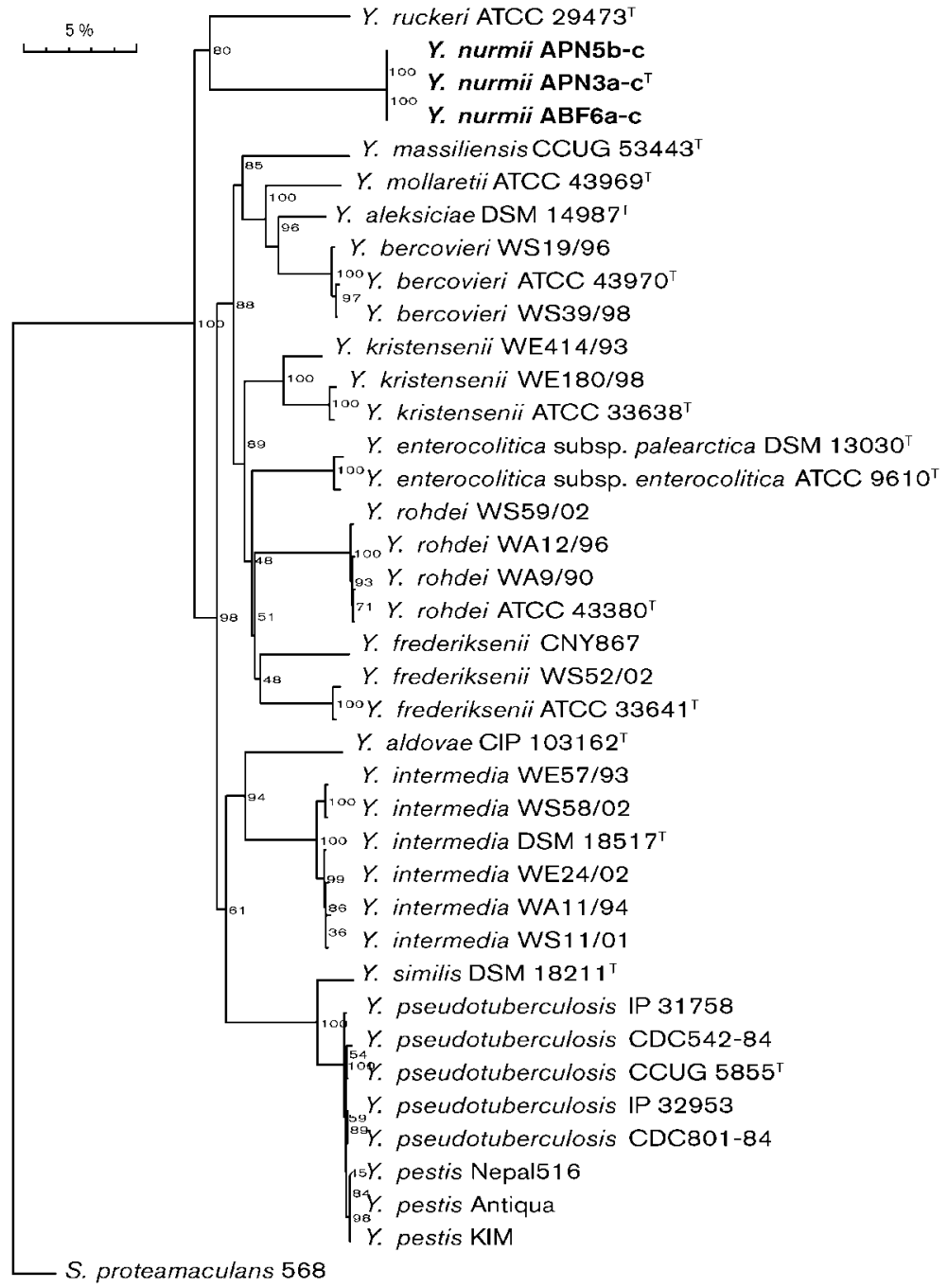

Fig. 2. Neighbour-joining tree based on concatenated $g \ln A, \operatorname{gyr} B, \mathrm{HSP} 60$ and $\operatorname{rec} A$ gene sequences of Yersinia nurmii sp. nov. and type and reference strains of the genus Yersinia. Bootstrap values (\%) for 1000 replicates are given at branch points. $S$. proteamaculans was used as outgroup. Bar, $5 \%$ difference in nucleotide sequence. observation. The strains were oxidase-negative and catalase-positive. The biochemical characteristics of the strains are presented in Table 2 and are compared with those of other Yersinia species. Strains ABF6a-c, APN5b-c and APN $3 a-c^{T}$ did not hydrolyse urea and did not ferment Larabinose. The API 20E profile obtained for ABF6a-c, APN5b-c and APN3a-c ${ }^{T}$ was 3307121 (99.7\% identity with Cedecea davisae). The phenotypic profile of strains APN5b-c, ABF6a-c and APN3a-c ${ }^{T}$ was most similar to that of Y. ruckeri.

Based on the results of the polyphasic taxonomic study described above, strains ABF6a-c, APN5b-c and APN 3a-c ${ }^{T}$ represent a novel species of the genus Yersinia, for which the name Yersinia nurmii sp. nov. is proposed.

\section{Description of Yersinia nurmii sp. nov.}

Yersinia nurmii (nur'mi.i. N.L. gen. masc. n. nurmii of Nurmi, in honour of the late Professor Esko Nurmi, a distinguished researcher in the field of food hygiene, who, with his colleagues, introduced, among other things, the concept of competitive exclusion).
Cells are Gram-negative, motile rods with multiple flagella. Their length varies between 0.8 and $1.9 \mu \mathrm{m}$ after $24 \mathrm{~h}$ incubation on blood agar at $28{ }^{\circ} \mathrm{C}$. Oxidase-negative, catalase-positive and negative for urea hydrolysis. Positive for utilization of glycerol and ONPG, ornithine decarboxylase, Voges-Proskauer reaction and lipase. Hydrolyses gelatin. Ferments trehalose and sucrose. Ferments lactose and cellobiose weakly. Negative for utilization of D-xylose, adonitol, sorbose, aesculin, salicin and raffinose, fermentation of inositol, sorbitol, melibiose, rhamnose and Larabinose, lysine decarboxylase and indole production. Grows on blood, tryptic soy, MacConkey and nutrient agar at $25-37{ }^{\circ} \mathrm{C}$ and produces $1.0-1.5 \mathrm{~mm}$ colonies on blood agar at $28{ }^{\circ} \mathrm{C}$ in $24 \mathrm{~h}$. Colonies are circular and convex with elevated centres. The DNA G $+\mathrm{C}$ content is $48.7 \mathrm{~mol} \%$. $16 \mathrm{~S}$ rRNA gene sequence similarity with the phylogenetically most closely related species, Y. ruckeri, is $98.0 \%$.

The type strain is APN3a-c ${ }^{\mathrm{T}}$ (=DSM $22296^{\mathrm{T}}=\mathrm{LMG}$ $25213^{\mathrm{T}}$ ), isolated from broiler meat packaged under a modified atmosphere. Reference strains are ABF6a-c and APN5b-c. 
Table 2. Biochemical characteristics of Yersinia nurmii sp. nov. compared with those of type strains of other Yersinia species

Type strains: 1, Y. nurmii sp. nov.; 2, Y. ruckeri; 3, Y. mollaretii; 4, Y. aldovae; 5, Y. bercovieri; 6, Y. intermedia; 7, Y. rohdei; 8, Y. enterocolitica subsp. enterocolitica; 9, Y. enterocolitica subsp. palearctica; 10, Y. aleksiciae; 11, Y. frederiksenii; 12, Y. kristensenii; 13, Y. pestis (Sprague et al., 2008); 14, Y. pseudotuberculosis; 15, Y. similis; 16, Y. massiliensis. All data are from this study unless otherwise indicated. +, Positive; -, negative; (+), weakly positive after $48 \mathrm{~h}$ incubation. All strains were positive for utilization of trehalose and glucose and negative for utilization of adonitol.

\begin{tabular}{|c|c|c|c|c|c|c|c|c|c|c|c|c|c|c|c|c|}
\hline Characteristic & 1 & 2 & 3 & 4 & 5 & 6 & 7 & 8 & 9 & 10 & 11 & 12 & 13 & 14 & 15 & 16 \\
\hline \multicolumn{17}{|l|}{ Utilization of: } \\
\hline D-Xylose & - & - & + & + & + & + & + & + & - & + & + & + & + & + & + & + \\
\hline Aesculin & - & - & $(+)$ & - & - & + & - & - & - & - & + & - & + & + & + & + \\
\hline Salicin & - & - & $(+)$ & - & $(+)$ & + & $(+)$ & - & - & $(+)$ & + & + & - & + & $(+)$ & + \\
\hline Cellobiose & $(+)$ & - & + & - & + & + & + & + & + & + & + & + & - & - & - & + \\
\hline Raffinose & - & - & - & - & - & + & + & - & - & - & - & - & - & - & - & - \\
\hline Glycerol & + & + & + & + & $(+)$ & + & + & + & + & + & + & + & - & $(+)$ & + & + \\
\hline Citrate & + & - & + & + & - & + & + & - & - & - & + & - & - & - & + & + \\
\hline Inositol & - & - & $(+)$ & + & - & + & - & $(+)$ & + & $(+)$ & + & $(+)$ & - & - & - & + \\
\hline Sorbitol & - & - & + & + & + & + & + & + & + & + & + & + & - & - & - & + \\
\hline Melibiose & - & - & - & - & - & + & + & - & - & - & - & - & - & + & - & - \\
\hline Urea hydrolysis & - & - & + & + & + & + & + & + & + & + & + & + & - & + & + & + \\
\hline Lysine decarboxylase & - & + & - & - & - & - & - & - & - & - & - & - & - & - & - & - \\
\hline Ornithine decarboxylase & + & + & + & + & + & + & + & + & + & + & + & + & - & - & - & + \\
\hline $\begin{array}{l}\text { Voges-Proskauer } \\
\text { reaction }\end{array}$ & + & - & - & + & - & + & - & - & - & - & + & - & - & - & - & - \\
\hline Indole production & - & - & - & - & - & + & - & + & - & - & + & + & - & - & - & + \\
\hline
\end{tabular}

\section{Acknowledgements}

We are grateful to the Academy of Finland for supporting our research financially through the ELVIRA programme (decision no. 1117921) and through funding to the Finnish Centre of Excellence in Microbial Food Safety Research (decision no. 1118602). We thank E. Merivirta for her technical assistance.

\section{References}

Atlas, R. M. \& Snyder, J. W. (2006). Handbook of Media for Clinical Microbiology, 2nd edn. Boca Raton, FL: CRC Press.

Bottone, E. J., Bercovier, H. \& Mollaret, H. H. (2005). Genus XLI. Yersinia. In Bergey's Manual of Systematic Bacteriology, 2nd edn, vol. 2B, pp. 838-848. Edited by G. M. Garrity. New York: Springer.

Cashion, P., Holder-Franklin, M. A., McCully, J. \& Franklin, M. (1977). A rapid method for the base ratio determination of bacterial DNA. Anal Biochem 81, 461-466.

De Ley, J., Cattoir, H. \& Reynaerts, A. (1970). The quantitative measurement of DNA hybridization from renaturation rates. Eur $J$ Biochem 12, 133-142.

Fredriksson-Ahomaa, M., Hielm, S. \& Korkeala, H. (1999). High prevalence of yadA-positive Yersinia enterocolitica in pig tongues and minced meat at the retail level in Finland. J Food Prot 62, $123-127$.
Huß, V. A. R., Festl, H. \& Schleifer, K. H. (1983). Studies on the spectrophotometric determination of DNA hybridization from renaturation rates. Syst Appl Microbiol 4, 184-192.

Kandolo, K. \& Wauters, G. (1985). Pyrazinamidase activity in Yersinia enterocolitica and related organisms. J Clin Microbiol 21, 980-982.

Kotetishvili, M., Kreger, A., Wauters, G., Morris, J. G., Jr, Sulakvelidze, A. \& Stine, O. C. (2005). Multilocus sequence typing for studying genetic relationships among Yersinia species. J Clin Microbiol 43, 2674-2684.

Niskanen, T., Laukkanen, R., Murros, A., Björkroth, J., Skurnik, M., Korkeala, H. \& Fredriksson-Ahomaa, M. (2009). Characterisation of non-pathogenic Yersinia pseudotuberculosis-like strains isolated from food and environmental samples. Int J Food Microbiol 129, 150-156.

Pitcher, D. G., Saunders, N. A. \& Owen, R. J. (1989). Rapid extraction of bacterial genomic DNA with guanidium thiocyanate. Lett Appl Microbiol 8, 151-156.

Riley, G. \& Toma, S. (1989). Detection of pathogenic Yersinia enterocolitica by using Congo red-magnesium oxalate agar medium. J Clin Microbiol 27, 213-214.

Sprague, L. D., Scholz, H. C., Amann, S., Busse, H.-J. \& Neubauer, H. (2008). Yersinia similis sp. nov. Int J Syst Evol Microbiol 58, 952-958.

Xu, H. X., Kawamura, Y., Li, N., Zhao, L., Li, T. M., Li, Z. Y., Shu, S. \& Ezaki, T. (2000). A rapid method for determining the $\mathrm{G}+\mathrm{C}$ content of bacterial chromosomes by monitoring fluorescence intensity during DNA denaturation in a capillary tube. Int $J$ Syst Evol Microbiol 50, 1463-1469. 